\title{
PEDAGOGY OF PEERS: CULTIVATING WRITING RETREATS AS COMMUNITIES OF ACADEMIC WRITING PRACTICE
}

\section{S. Benvenuti}

Assistant Dean for Teaching and Learning for the Faculty of Commerce, Law and Management

School of Economic and Business Sciences

University of the Witwatersrand

Johannesburg, South Africa

e-mail: susan.benvenuti@wits.ac.za

\section{ABSTRACT}

Pressure related to research publication output continues, heightened by growing numbers of early career academics. Writing retreats, designed around the pedagogy of community of practice, have potential to initiate early career academics into core academic practices including peer review, and draw them into the community of 'academics as writers'. However, a series of four semi-structured writing retreats based on this pedagogy revealed that supporting novice writers' trajectory of progress from peripheral through to expert participation is challenging. Careful attention must be paid to balancing the design of the retreat, the 'construction' of the retreat community of practice and the engagement of participants on retreat. Skilfully managed, these writing retreats can support academic writing development, and deliver benefits to academics, from novice to established, that include enhanced research publication output, strengthened academic identity as writers and a motivated community of practice extending beyond the writing retreats.

Keywords: writing pedagogy, writing retreat, academic practice, community of practice, early career academic development, academic writing

\section{INTRODUCTION}

At the risk of stating the obvious, publishing, frequently and in the right places, remains a priority for academics whether early career or established (Dankoski et al. 2012; McGrail, Rickard and Jones 2006; Morss and Murray 2001). Promotion, confirmation or tenure, and access to research or grant funding are tightly linked to research publication productivity. The current constrained context makes research-generated income increasingly important to South African universities, placing research productivity under scrutiny. Research publication units are tracked and reported from individual researcher through discipline/department/ school/faculty to overall university levels, affecting budget allocations within universities and across the sector. International university ranking standings are also heavily influenced by research output. 
Pressure is heightened in 'research intensive' universities or where faculties or schools are so-called bottom heavy, with a larger percentage of staff either young or early career academics, or in positions that previously did not require research publication. Growing calls to transform the academic community in higher education have resulted in higher levels of young or early career academics. Another concern is the 'ageing' of prolific publishers.

The State of Science in South Africa (2009) reports that research in ISI journals disaggregated across 20 scientific fields indicates 'a significant ageing of publishing scientists over the period 1990 to 2004. In nine of these fields, more than half of all outputs are being produced by authors over the age of 50.' This figure was 74 per cent in the education field.

Universities therefore need to find ways to support high levels of subsidy-yielding research publication and develop emerging academics. Writing retreats have become popular with writers looking for focused, undisturbed time in which to write (Moore 2003), and an established body of literature (Moore, Murphy and Murray 2010; Murray and Newton 2009; Murray and Moore 2006; Grant 2006) argues that writing retreats offer distinct benefits across a variety of needs. This literature explores different models or formats of retreats and how these support different writing or academic needs, but little is published on the complexity of teaching and learning academic writing and specific pedagogies underlying writing retreats. Austerity measures in higher education leave writing retreats open either to dismissal as expensive escapism to do what should be done as part of normal academic life (Grant 2006, 485) or possibly worse, naively seen as the silver bullet to fix what is fast emerging as another deficit model in higher education, namely academic research productivity.

Grant (2006) attests to the difficulty of measuring the contribution of writing retreats and is backed by Aitchison, Kamler and Lee's (2010) argument for making the hidden pedagogy of academic writing and publication more visible. The economic pressure in higher education forces us to defend investment in interventions designed to improve research publication, but it is arguably equally important to question and examine writing development and more broadly professional academic development in the setting of writing retreats.

\section{RESEARCH AIMS AND OBJECTIVES}

In response to the situation described in the Introduction, this article presents a case study that reflects on a series of four Community of Practice (CoP) based writing retreats held over a period of two years, which were introduced to address research productivity at all levels in an under-performing, bottom heavy school. As one of three facilitators of these retreats, I examine the retreats in terms of their contribution to publication rates and more importantly, to 
professional academic development, in particular for early career academics. I describe the rationale and pedagogic intent behind the structure, design and ongoing refining of the retreats in light of the intended participants' stated and perceived needs. Using pre-retreat participant input and post-retreat evaluations, facilitator observations and reported publication output of the participants, I critically reflect on the intended retreat outcomes against the following guiding questions:

- Who is most likely to benefit from these particular models of retreats and what conditions are likely to support this?

- What are the challenges associated with artificially constructing a CoP?

- What is the role of retreat facilitators in supporting initiation into and ongoing participation in, a community of academic writing practice?

In light of this, I argue that designing writing retreats around a pedagogy of CoP has the potential not only to deliver increased research output, but also to provide means through which early career academics can be drawn into the community of 'academics as writers' and initiated into core academic practices such as peer review. By re-imagining a retreat as focused time and space in which to legitimately participate in a research writing $\mathrm{CoP}$ and providing appropriate guidance, it is possible for early career academics to be supported in their trajectory from peripheral, to novice and then on to expert participation (Lave and Wenger 1991).

\section{INTRODUCING THE CASE STUDY}

The retreats under focus in this study were designed to address the specific problem of an underproductive school in terms of research publication. The school, situated in a commerce faculty at a research-intensive university, houses approximately 80 academics across several disciplines. The school was recognised as 'bottom heavy' with a large number of young staff members, many employed on short-term contracts as associate lecturers to lecture undergraduate courses while they complete either Masters or PhD degrees. A skills shortage in the country ensures attractive employment opportunities in the commercial sector, resulting in high turnover of associate lecturers who seldom stay on beyond their graduation. In addition, a group of academics originally appointed purely as academic tutors to meet the demands of very large undergraduate numbers, are now expected to produce research output, despite many not holding higher degrees.

With research output measured per capita, schools with many junior staff and high 
turnover struggle to meet university research targets. A recently appointed head of school applied for university research development funding to increase the publication rate in the school. Writing retreats were identified as a way of addressing the low research output rates across all staff levels: for senior staff by providing focused and protected time and space for writing; and for young or early career academics, by providing the necessary input and support needed to complete higher degrees or publications (Petrova and Couglin 2012).

The design of the first writing retreat is best described as experimental, both because it used writing retreats to address a multitude of challenges relating to research output, and because it provided the potential for a diverse group of 'writing retreatants'. Drawing on our experiences of writing retreats, research writing courses and adult education pedagogies, the facilitators decided on a model of semi-structured residential writing retreats. This hybrid approach sought to combine time and space for writing, with providing know-how and guidance through mini workshop sessions, while participating as part of a community of writers.

\section{CONCEPTUAL FRAMEWORK}

Writing retreats are widely acknowledged as one means through which to support writers (Morss and Murray 2001; Moore 2003; Grant 2006; Murray and Newton 2009). The varied ways in which they can be viewed, construed, structured and delivered, enables different goals and outcomes to be achieved.

Murray and Newton (2009) focus on the idea of writing retreats as potential sites of communities of practice learning. In particular, they argue that retreat participants could be viewed as engaging in legitimate peripheral participation (Lave and Wenger 1991, 36) as 'a writing retreat could be seen as a "legitimately peripheral” activity'.

Communities of Practice, in their conception, interpretation and application have varied and evolved over time (Cox 2005; Li et al. 2009). Emerging initially as social learning systems in contrast to classroom-based cognitivist theories ( $\mathrm{Li}$ at al. 2009), CoP encompass situated newcomer learning (Lave and Wenger 1991); organisational learning for innovation (Brown and Duguid 1991); professional identity development and participation trajectories (Wenger 1998) and the application of CoP to organisational value creation (Wenger, McDermott and Snyder 2002).

The conceptual framework for this study draws on research publication deficits that serve to create negative pressure on academics to publish. I view this deficit model against writer identity, motivation and perseverance, as writing enablers that are difficult to achieve in the face of negative pressure. Using the varied and evolving conceptions of CoP, I examine the 
possibility of cultivating writing retreats as CoP - to provide the pedagogy and facilitating environment for academic identity and writing development, as well as support for enhanced levels of publication.

\section{Research publication - deficits and deficiencies}

Pressure to publish and sanctions and costs associated with not publishing (promotion, increases, teaching loads, etc.) appear to nourish a negative outlook on research publication by academics. Murray and Moore suggest that instead of serving to build the academy, 'academic writing has become a thorn in [its side]' (2006, xi). Academic writing has become for many a black cloud, ever present, hovering and 'experienced as stressful and threatening' (Chandler, Barry and Clark 2002). This anxiety is fed by suggestions that non-publishing academics are deficient, despite being in their roles precisely because of their intellectual abilities and proven academic track record.

Blaxter, Hughes and Tight (1998) dispute a wide-spread assumption that a 'good' academic or researcher should automatically be able to write. Olthouse (2013) supports this, arguing that talent or ability in one area may not necessarily transfer to another, but that people can potentially perform at high levels if given appropriate support. Sustained effort and perseverance are also required.

Additionally, some of these so-called deficiencies are not directly related to writing or even research. Time-management, workloads, institutional policies and hidden vagaries of the research or higher degrees process may all conspire against young and/or inexperienced academics. Lacking guidance and support in managing tricky balancing acts and resulting motivation issues, many young academics do not see value in pursuing academic life beyond acquiring the desired higher degree. Lave and Wenger's (1991) original conception of CoP as situated learning by newcomers occurring through social interactions in the workplace, suggests that opportunity for interactions between novices and more experienced academics while undertaking the practice of writing in a supportive and conducive environment can support writing development. Observation of practices and behaviours in action is recognised as an efficient way of developing complex skills and knowledge (Bandura 1977).

\section{Writer identity, motivation and perseverance}

Fiction writers, successful ones, persevere despite a career that poses many obstacles and uncertainties, and they persevere because they are motivated by engaging in something they perceive as meaningful (Gouthro 2014). Further, they identify themselves as writers, despite 
the majority of them (at least initially) holding a 'day job’.

Wenger $(1998,149)$ claims that 'there is a profound connection between identity and practice'. Do academics identify themselves as writers, or as researchers who have to write? Does their view of academic practice include writing as a key area of their work?

Motivation theorists, for example Ryan and Deci (2000), suggest that intrinsic motivation, as described above by Gouthro (2014) is what enables deep learning and supports perseverance in the face of adversity. Extrinsic motivation, driven by external forces of pressure or even reward, is seen as less likely to inspire or sustain perseverance, particularly in the face of difficulties and tasks that are viewed as unpleasant (Ryan and Deci 2000). Self-determination theory allows for extrinsic motivation to encourage action based on acknowledged utility, but argues that engagement is likely to be less than in the case of intrinsically motivated engagement (Deci and Ryan 1985). I therefore question whether academics, who might neither identify themselves as writers nor be intrinsically motivated to write, will persevere in developing writing skills and overcoming other publication obstacles (peer review, time pressures) to meet the growing levels of research publication demanded.

Wenger (1998) shifted focus towards identity development and a stronger definition of CoP as commonly held understanding, goals, and resources and jargon (Li et al. 2009). While academics are not necessarily working together on projects or problems, viewed as a community, academic work exhibits many of Wenger's fourteen indicators for the existence of a CoP (1998). This is useful in contemplating how to develop necessary competencies and strengthen professional identity.

\section{Writing retreats as opportunities for academic writing development and enhanced research publication}

In Cultivating Communities of Practice: A Guide to managing knowledge, Wenger, McDermott and Snyder (2000) switch from the assertion that CoP emerge spontaneously, to actively engineering CoP to enhance organisational value ( $\mathrm{Li}$ et al. 2009). They suggest that CoP can deliver value by 'connecting the personal development and professional identities of practitioners to the strategy of the organisation' (Wenger, McDermott and Snyder 2002, 17). While this has been viewed as a 'popularisation and a simplification but also a commodification of the idea of community of practice' (Cox 2005) it does provide guidance in how to use CoPs and principles for cultivating them (Wenger, McDermott and Snyder 2002).

The pedagogical framing for the retreats in this study takes licence from the tradition of varied interpretations and applications of CoP (Cox 2005). It begins by drawing on the premise 
that cultivating a CoP can serve to deliver value to the university by connecting the individual writing and identity development needs of academics to the university's need for enhanced publication output. To do this, the facilitators sought to create the opportunity and support to engage in what we considered to be important shared academic writing practices, which we situated within a CoP of academics on retreat.

\section{Shared practices of academic writing}

For many young academics, The Academy is daunting and mysterious. Although now in theory part of this community, expected to teach, assess and publish, early career academics, particularly in South African universities, are often still postgraduate students. There is little formal induction into academic practice, with only the lucky few working with mentors or sympathetic senior colleagues. The majority learn their academic writing skills by dealing with supervisor or reviewer comments, a difficult and potentially traumatic process for inexperienced writers (Blaxter, Hughes and Tight 1998). I therefore argue that so-called shared practices are not so much shared as experienced in isolation.

Most pervasive of these shared practices is peer review, and ironically this is far from 'peer' based when it comes to novice writers. Experienced academics provide so-called peer reviews, often couched in language that needs translation for the early career academic. Lee and Kamler $(2008,516)$ argue in the context of doctoral education that 'As a pedagogical principle, peer review is a "horizontalizing” process in which student-peers work together and with more experienced researchers and writing specialists to develop expertise in different aspects of research writing, at the same time as entering explicitly into a network of peer relations as becoming researchers'. They describe a pedagogical duality of 'being- and becoming-peer'. This is seen as a move from hierarchical power relationships, studentsupervisor or novice-experts, to more networked, community-based pedagogy (Lee and Kamler 2008; Aitchison and Lee 2006; Boud and Lee 2005).

The second shared practice important to highlight in a retreat pedagogy is writing as a process of drafting and revising. This enables focus beyond the novice writer to include established academics whose inner peer-reviewer and full time critic has developed to the point of being far more brutal than the anticipated journal reviewer (Badenhorst 2007). Academics become paralysed by this inner voice: unable to draft with the intention to review; unable to write unless it feels perfect. Novice writers have a different problem albeit with the same effect of discouraging writing: in reading for their higher degrees or research projects, they read the 'good journals', the seminal articles, and therefore only see excellent finished products. They 
are not privy to the numerous previous versions, revisions and possible prior rejections.

A third important writing practice to make explicit as a shared practice, is writing as an integral part of the whole research process, not just the means to wrap it up and present the results. Wolcott $(1990,21)$ contends, 'The conventional wisdom is that writing reflects thinking. I am drawn to a different position: writing is thinking ...'. Exploring different ways of writing and learning different approaches and techniques, such as focused freewriting, can move a writing and research project forward by producing writing that either evolves through drafts into part of the final product, or moves the thinking forward. Both Castle's and Keane's articles within this special edition, talk to the benefits of freewriting.

The above shared practices are easily incorporated into writing retreats. As students build knowledge and skills gradually, recognising acquired knowledge and applying it in different contexts over time as they become more confident, so too can novice academic writers experience and learn shared practices in supported environments (Galligan et al. 2003; Li et al. 2009). Writing retreats provide diverse means of giving and receiving writing support, through facilitators and other participants (peers in the academic context), formal workshop sessions and informal feedback and review (Moore, Murphy and Murray 2010). This learning can be said to be both situated within a CoP (Lave and Wenger 1991), and socially mediated and constructed. Although the writing retreats included all three of the above shared practices, this article only looks at peer review in detail as it gave rise to some interesting challenges.

\section{Writing retreats as communities of academic writers}

Elbow and Sorcinelli (2006) recommend focusing writing retreats on opportunities: to include all academics especially early career, to link academic work with a sense of belonging to a community of scholars, to draw on expertise within the community for input where needed. They talk of participants becoming 'allies rather than trying to compete with each other' (2006, 22) and suggest that both identity as writers and CoP can be developed. Murray (2012) notes that communities of research are useful motivators for writers. For early career academics and novice writers, peer review, drafting and revising, as well as writing at various stages can be observed and experienced first-hand. They can 'peer review' with actual peers who are less threatening in their feedback and whose papers are less stressful to review, while observing more experienced academics both offering and responding to peer review - a safe, effective learning space (Bandura 1977). They can watch a draft take shape over a few days, and 'play' with focused freewriting, all the while undertaking actual academic writing practices or 'engaging in the target activities’ (Moore, Murphy and Murray 2010, 24) as part of a community 
of writers, writing.

\section{RESEARCH DESIGN AND PROCESS}

This study adopted an interpretive and evaluative approach across a variety of sources and types of data, looking across the series of retreats as the design and implementation evolved.

As the retreat design was experimental and initial funding had been obtained for two retreats, it was important for the facilitators to be able to review the first retreat and make changes in future iterations. Detailed retreat evaluations were conducted to meet reporting obligations. Permission was obtained from respondents to use retreat evaluations for both reporting to research funders and for research purposes. Further, participants were asked to contribute pieces of free writing, goal setting, etc. at the end of each retreat if they were open to these being used for research purposes. Permission was also sought for facilitators to observe sessions of the retreats and make notes, with the undertaking that participants would not be identifiable in the data.

The necessity to report on the writing retreats in order to obtain funding for further retreats ensured that a variety of data was collected during each retreat. This helped to ensure credibility in the study through data triangulation (Lincoln and Guba 1981; Maxwell 2005). Prolonged engagement (Lincoln and Guba 1981) and intense, long-term involvement (Maxwell 2005) further supports credibility in such a study. In presenting the reflection and discussion I have tried to provide a rich text description as suggested by Rule and John (2011) to enhance transferability and broaden understanding across contexts.

\section{DESCRIPTION, REFLECTION AND DISCUSSION}

I begin by describing the retreats focusing on their design and implementation ('cultivation') with reference to Wenger, McDermott and Snyder’s CoP design principles (2002). I explain the application and selection process, choice of mini-workshop sessions and thinking behind the organisation of the retreat days and activities. Thereafter I briefly describe the participants (typical experience and needs), and reflect on the effectiveness of the flexibility of a semistructured design and the potential contribution of the CoP to deliver benefits across the variety of retreat participant needs.

I follow this general reflection with a look at the effectiveness of these retreats in terms of establishing or supporting participation in the identified shared academic writing practice of peer review. Here, the guiding questions for the research listed earlier are used to focus the reflection. Finally I return to the overarching question of viewing retreats as being a site of peer 
pedagogy situated within a community of academic writing practice.

\section{'Cultivating' the CoP based writing retreats - design principles}

Wenger, McDermott and Snyder (2002) describe spontaneously formed CoP as having an 'aliveness' about them, which attracts members to a community and sustains its existence. A challenge therefore in cultivating $\mathrm{CoP}$ is designing them in such a way as to achieve this 'aliveness'. Seven principles of design were identified: 'design for evolution; open a dialogue between inside and outside perspectives; invite different levels of participation; develop both public and private community spaces; focus on value; combine familiarity and excitement; create a rhythm for the community' (Wenger, McDermott and Snyder 2002, 51-63). In my description of the retreats that follows, I identify aspects of them which may be linked to these CoP design principles.

The retreats were five day residential, off-campus retreats with an option of being a 'day participant'. The venues used are smallish boutique hotel/lodges situated close to campus. Each day began with breakfast providing a social start to the day. The group then assembled in the main 'conference room' for a check-in and kick-starting writing activity - normally a focused freewrite, often with a creative spin to it. The first session of each retreat is used to set the scene for the week: facilitators introduce themselves, explain the structure of the retreat, briefly introduce mini-workshop sessions on offer and motivate for the few ground rules of the retreat. These rules include being present and participating in writing activities for the duration of the retreat, participating in peer review sessions and supporting the group's opportunity for writing by respecting the need for privacy and quiet as desired.

Writers then move into their chosen rhythm and activities for the rest of the day. Optional mini-workshops are offered in the mornings. The venues are specifically chosen for the availability of spaces to write alone, rooms for collaborative writing activities, and beautiful large gardens perfect for writing, thinking, walking or discussions. A coffee/tea station is available all day and into the evening, together with catered snacks and lovely meals. The group gathers after lunch each day to share writing and peer review in small groups. Afternoons are spent writing or working with the facilitators. Early dinner is available to enable day participants to enjoy a meal with the group before heading home. Evenings are spent as desired - writing, reading, one-on-one discussions, impromptu writing group meetings, and so on. Figure 1 shows a typical programme for a five day retreat. 


\begin{tabular}{|c|c|c|c|c|c|c|}
\hline \multirow[b]{2}{*}{ 8:00 } & & Monday & Tuesday & Wednesday & Thursday & Friday \\
\hline & & BREAKFAST & BREAKFAST & BREAKFAST & BREAKFAST & BREAKFAST \\
\hline 9:00 & $\begin{array}{l}\text { Group } \\
\text { Morning } \\
\text { Sessions } \\
\text { (All) }\end{array}$ & \multirow{2}{*}{$\begin{array}{l}\text { Retreat Launch } \\
\text { - Value } \\
\text { Proposition - } \\
\text { why are we } \\
\text { here? } \\
\text { - Ground Rules } \\
\text { - SMART Goal } \\
\text { Setting } \\
\text { - I'm saying } \\
\text { YES to ... } \\
\text { and NO to ... } \\
\text { - Retreat } \\
\text { Structure } \\
\text { - What's On? } \\
\text { - Intro to Free } \\
\text { Writing } \\
\text { - Peer review } \\
\end{array}$} & $\begin{array}{l}\text { Creative Free } \\
\text { Writing - The } \\
\text { Journey this } \\
\text { Week } \\
\text { Barriers to } \\
\text { writing }\end{array}$ & $\begin{array}{l}\text { Free writing - } \\
\text { about how I write } \\
\text { on retreat } \\
\text { Constructive } \\
\text { criticism - being a } \\
\text { critical reader }\end{array}$ & $\begin{array}{l}\text { Free writing - } \\
\text { why I listen to } \\
\text { the critic within } \\
\text { The writing } \\
\text { cycle - } \\
\text { silencing the } \\
\text { critic - drafting } \\
\text { and editing }\end{array}$ & $\begin{array}{l}\text { Free writing - } \\
\text { my writer } \\
\text { identity } \\
\text { Collaborative } \\
\text { session - } \\
\text { building and } \\
\text { maintaining } \\
\text { the writing } \\
\text { momentum }\end{array}$ \\
\hline 10:00 & \multirow{3}{*}{$\begin{array}{l}\text { Writing Time } \\
\text { (workshops } \\
\text { and activities } \\
\text { available as } \\
\text { shown) } \\
\text { Tea/Coffee } \\
\text { station on } \\
\text { offer }\end{array}$} & & $\begin{array}{l}\text { Writing } \\
\text { Introductions }\end{array}$ & Building the Body & Concluding & Writing Time \\
\hline $11: 00$ & & $\begin{array}{l}\text { Tea Break } \\
\text { The Technical } \\
\text { Issues of Writing } \\
\text { for Publication }\end{array}$ & Writing Time & Writing Time & Writing Time & Writing Time \\
\hline $12: 00$ & & Writing Time & Writing Time & $\begin{array}{l}\text { Academics as } \\
\text { Writers }\end{array}$ & Writing Time & $\begin{array}{l}\text { Refining } \\
\text { Writing }\end{array}$ \\
\hline $13: 00$ & & LUNCH & LUNCH & LUNCH & LUNCH & LUNCH \\
\hline $14: 00$ & $\begin{array}{l}\text { Collaborative } \\
\text { Writing (All) }\end{array}$ & \multicolumn{4}{|c|}{ Small group reading and peer review sessions } & \multirow{4}{*}{$\begin{array}{l}\text { Retreat } \\
\text { Closing } \\
\text { Reflection } \\
\text { Drinks and } \\
\text { snacks to } \\
\text { close by 3:30 }\end{array}$} \\
\hline $15: 00$ & $\begin{array}{l}\text { Individual } \\
\text { Writing Time }\end{array}$ & \multicolumn{4}{|c|}{ Writing Time - opportunity for one-on-one engagement if desired } & \\
\hline 17:00 & $\begin{array}{l}\text { Group } \\
\text { Review of } \\
\text { the day }\end{array}$ & \multicolumn{4}{|c|}{$\begin{array}{l}\text { Reflection time for the whole group on how the writing, reviewing etc. went } \\
\text { for the day }\end{array}$} & \\
\hline $18: 30$ & & DINNER & DINNER & DINNER & DINNER & \\
\hline
\end{tabular}

Figure 1. A sample retreat programme

Viewing the above in light of Wenger, McDermott and Snyder's seven design principles, most feature in some way (2002). Designing for evolution of the CoP requires allowing for flexibility and change over time as the community develops, matures and identifies different priorities. In the case of the writing retreats, the CoP has a limited lifespan in one way - the five days of a retreat, but in another, continues (with breaks) across the four retreats and beyond as academics informally continue to work together. The different make-up of the CoP each time in terms of needs, and newness or otherwise to the community, allows for this evolution.

Meeting off campus, in fairly luxurious spaces with the indulgence of catering and overnight accommodation provides the factor of excitement and newness weighed up against the familiarity of working with known colleagues. The venues provided both public and private spaces for the CoP to work in. The flexibility of the programme, with choices and options, 
invited participants to engage at different levels in particular activities. The semi-structured programme that changed slightly across the four retreats, helped writers to find their own rhythms which in turn contributed to a CoP rhythm. Overall, the commitment to writers and investment in the writing retreats signalled that the members of the CoP were valued and that their undertakings were important (Wenger, McDermott and Snyder 2002).

The choice of mini-workshops offered was based on issues covered in writing workshops, contained in other retreat designs or covered as part of research publication writing retreats (Kapp, Albertyn and Frick 2011). Would-be participants were required to provide a motivation for attending and a self-reported assessment of their level of experience of research writing (novice - no prior publications; emerging - one or two conference papers/journal articles in the past five years; established - conferences and three or four articles in the past five years). They were asked to indicate level of need or interest against a list of 18 'Areas of Focus' that included the various mini-workshop topics as well as things such as one-on-one writing consultations, peer review and writing time. When finalising the design for the first of the four retreats, these 'input' responses were used to refine planning, particularly with respect to writing time and peer review. After the first retreat these were used to gauge interest and for some level of planning, but were valued as tools to build a profile of the expected retreat participants upfront. The input from literature, similar retreats and participants (both prior to and post attendance) provided the 'dialogue between inside and outside perspectives' of the CoP (Wenger, McDermott and Snyder 2002).

Facilitator observations and retreat evaluations and comments after the first and subsequent retreats were seen as reliable tools for retreat fine-tuning. Regardless of which workshop sessions participants chose to attend, at least four hours per day was set aside just for writing, with an additional hour each day for collaborative writing or peer review.

In total, 51 academics participated in the four retreats, three as facilitators (two females and one male) and 48 academics. Each retreat attracted 15 to 18 participants (excluding facilitators) and unusually, according to the literature (Moore, Murphy and Murray 2010 as just one example), had a majority of male academics in total at each retreat. These were not just early career males, six male associate professors attended, three more than once. Figure 2 shows the breakdown of attendees by gender, self-reported level of experience and repeat attendees.

As reasonably expected, most established researchers were only looking for quality time to write, with some expressing interest in peer review, or sessions like 'Barriers to writing', 'Developing good writing habits' or 'Narrative and expression'. Most applicants rated writing time as a priority; novice and emerging applicants indicated interests across the scope of the mini-workshops on offer, depending on where they were in the research process. 


\begin{tabular}{|c|c|c|c|c|c|c|c|c|c|}
\hline \multirow{2}{*}{ 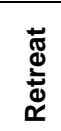 } & \multicolumn{2}{|c|}{ Facilitators } & \multicolumn{4}{|c|}{ Participant Details } & \multicolumn{3}{|c|}{$\begin{array}{l}\text { Self-reported level of experience of } \\
\text { participant researchers }\end{array}$} \\
\hline & Male & Female & Male & Female & Total & Repeat & Novice & Emerging & Established \\
\hline 1 & 1 & 2 & 11 & 4 & 15 & $\mathrm{n} / \mathrm{a}$ & 5 & 5 & 5 \\
\hline 2 & 1 & 2 & 12 & 5 & 17 & 2 & 5 & 7 & 5 \\
\hline 3 & 1 & 2 & 8 & 5 & 13 & 4 & 5 & 6 & 2 \\
\hline 4 & 1 & 2 & 9 & 6 & 15 & 6 & 6 & 7 & 2 \\
\hline
\end{tabular}

Figure 2. Breakdown of retreat participants for four writing retreats

We were able to accommodate all applicants each time as we had capacity at the venue. We still required applicants to motivate for attendance and insisted on completed forms indicating interests and needs. Each retreat started by setting goals through free writing which were shared amongst the group and posted up so that participants could revisit and revise their goals. They were asked to comment on their levels of satisfaction in achieving these goals in the post-retreat evaluations.

\section{Writing retreats as communities of practice}

Earlier I suggested that designing a writing retreat around a CoP has the potential to deliver increased research output, draw early career academics into the community of 'academics as writers', and introduce core academic practices such as peer review. Murray (2012) further notes that being part of a CoP enhances motivation to write. Before examining shared academic writing practice specifically, I consider the first guiding question:

- Who is most likely to benefit from these particular models of retreats and what conditions are likely to support this?

Semi-structured writing retreats were chosen to enable participants to achieve their particular goals by electing into or out of sessions on offer. Established academics generally focused on their writing and attended few if any mini-workshops. They valued the 'total immersion' (Moore, Murphy and Murray 2010) offered by the retreat. An established researcher reported 'not having access/being exposed to emails is very conducive to writing'

The venues were highly rated by virtually every participant, offering variety in writing spaces from private rooms or nooks, indoors and out, through to communal spaces to write, like the 'typing pool' model described by Murray and Newton (2009, 541). Those with a good selfknowledge in terms of their most productive writing environment, need for breaks and personal 
barriers to writing, benefitted most. 'I need to be alone to write efficiently' said one established researcher, while an emerging writer commented on the 'positive pressure of hearing and seeing others writing'. Some writers complained about having to break concentration to take scheduled meal or coffee breaks, despite these being flexible: 'I felt that in the day I could be doing more writing, but felt disrupted with the small breaks'. This was addressed by being far more explicit about retreat structure and participation in subsequent retreat introductions.

The flow of excellent food and facility to break for refreshments was highly appreciated by all retreat participants. 'Mega Great' was the verdict of a young male novice participant who completed large chunks of his thesis over three retreats. As is often acknowledged (Schneider 2003; Moore, Murphy and Murray 2010; Castle and Keane - forthcoming), an atmosphere of care and focus on physical well-being on writing retreats is an important way to support, encourage and reward writing endeavour to counter an otherwise negative, stressful and pressurised environment.

Both novice and emerging academics experienced difficulty achieving balance between attending workshops and use of uninterrupted writing time. Novice writers, lacking know-how and therefore confidence, seemed to feel obliged to attend all the workshops. Sometimes the presence of senior staff members or their supervisor added to this pressure; re-scripting the introductory talk (and retreat invitation) helped to mediate this problem. Novices were encouraged to use writing consultations with facilitators to help plan their retreat. They were advised on which workshops would support their retreat goals and assisted with prioritising time for writing. A returning novice participant said:

this time I came knowing what to expect. I knew exactly what I wanted to achieve and brought what I needed with me so I wouldn’t waste time during the retreat trying to find it. I also knew which workshops I needed to attend and only attended those - one I had attended before when I wasn’t ready for that section so it was a waste of time - this time I needed it.

Emerging writers seemed to use workshops as support when lacking confidence or to avoid writing when feeling overwhelmed or stuck. One-on-one consultations were used to support their focus for the retreat. Focused freewriting based on facilitators' observation was also useful. For example, freewriting first thing in the morning on the topic: 'On retreat I find I'm most productive when ...' can help writers think about the day ahead and take action to avoid previous days’ pitfalls or problems. When academics share their freewriting (Keane 2016) other retreat participants identify with common problems and concerns, which is comforting when shared by experienced colleagues. 


\section{Peer review}

Although used to reflect the idea of review by one's peers, peer review in the academic context is seldom a matter of equal standing. Initially daunting for all retreat participants, peer review appears to deliver most value for novice writers in retreat settings. After initial reservations, they use their novice status to push themselves more readily than emerging researchers, who because of their seniority to novice researchers, feel pressure to be good writers.

Lee and Kamler (2008) and Aitchison and Lee (2006) focus on peer review as a writing pedagogy in doctoral research writing development. South Africa has little by way of doctoral programmes; most doctoral students work exclusively with supervisor, relying on their input both to research and in terms of their writing. This is also true for early career academics undertaking higher degrees. Novice researchers are potentially worse off, relying entirely on reviewers' comments for input unless they are working with a sympathetic experienced colleague.

For facilitators, one of the goals of the writing retreats was to provide writers with the opportunity to engage with and in the practice of peer review. Lundstrom and Baker (2009) found that writers focusing only on providing peer review improved their own writing more than writers who only received peer review comments. The goal for the retreat CoP was to draw on available experience to provide feedback to writers and develop capacity for peer review in novice writers. This introduces the next guiding questions:

- What are the challenges associated with artificially constructing a CoP?

- What is the role of retreat facilitators in supporting initiation into and ongoing participation in, a community of academic writing practice?

Identifying a group of people as a CoP does not make them one ( $\mathrm{Li}$ et al. 2009). As Wenger, McDermott and Snyder (2002) suggest, the community has to be actively cultivated. One specific challenge is creating effective groups for peer review that allow for useful critical discussions and feedback that support positive outcomes.

One participant suggested, 'allow for sharing free-writing in smaller group or pairs. I think people are reluctant to share in a big group', but as facilitators we felt it might useful and less intense, if peer review happened in slightly larger groups. We had hoped a writer would get more diverse feedback from a bigger group and that discussion and debate over the advice might occur. Our first retreat revealed unexpected and interesting challenges in terms of peer review. 
An interesting observation relating to peer review groups within our retreat CoP was the role that established researchers played. We had expected established academics to help lead or facilitate peer review at least initially, and help initiate novice researchers into the practice. In many cases these established researchers were not comfortable with the idea of peer review and we experienced:

- Reluctance in offering either their own writing or concrete suggestions on other participants' writing, or limited to giving peer review.

- $\quad$ Limited writing focused input: many established researchers focused on research issues (methodology or content) despite requests for specific writing input.

- A general gravitation back towards the familiar role of supervisor and difficulty engaging as peers.

As facilitators we moved to counter this problem by encouraging writers to move between peer review groups, to step outside disciplinary boundaries to shift focus from content to writing, and by introducing writing exercises in morning sessions that focused on writing issues. We emphasised principles of feedback and modelled input to the groups. We demonstrated different types of feedback, differentiating technical issues (spelling, grammar and layout) from writing issues of clarity, argument or structure. When groups had less available work to provide input on, facilitators turned the sessions into discussions on writing or writing issues. This proved generative in providing writers with language to discuss writing or prompting writers to share a piece of work relating to the discussion.

Novice and emerging researchers settled into self-selected peer review groups ranging from three or four writers to six to eight. Initially, only more confident writers shared pieces of their work. As retreat participants grew more confident in their writing (Devlin and Radloff 2014) and familiar with asking for and offering feedback, more writers participated, supporting Moore's (2003) and Lee and Boud's (2003) assertions that peer support can support motivation.

Established researchers typically avoided peer review sessions (ostensibly in favour of working) or formed a peer group of other established writers. Some embraced the culture of peer review with other participants.

Peer review sessions were easier to manage in subsequent retreats for several reasons. The facilitators were the same and therefore had a shared understanding of what we were trying to achieve and pitfalls to avoid. A CoP of academic writers was also starting to emerge within the school, particularly amongst staff electing to attend the retreats. Returning participants were 
generally willing and experienced peer reviewers at subsequent retreats (Moore, Murphy and Murray 2010; Grant 2006) which enabled groups to form and start working earlier. Keen novices came with work that they were ready and willing to share which had a similar effect.

\section{CONCLUSION}

Writing retreats designed around $\mathrm{CoP}$ pedagogy can provide focused time and space to legitimately participate in a research writing $\mathrm{CoP}$, initiating early career academics into core academic practices such as peer review, drawing all academics into the community of 'academics as writers' and strengthening writer identity. Further, they allow flexibility in catering to varied retreat participant needs and opportunities to engage and collaborate with other writers. This contributes to enhanced research output for both academics and institutions by addressing some of the issues that prevent research publication.

Successful engagement and trajectory of progress from peripheral, to novice and then expert participation (Lave and Wenger 1991; Wenger 1998), requires careful attention to the 'cultivation' of the retreat CoP (Wenger, McDermott and Snyder 2002) and developing a different understanding of peers. Experience in running these writing retreats suggests that successful balancing of 'know-how input' against time for engagement in shared academic writing practices, relies on careful design and planning of each retreat.

This in turn requires knowledge of retreat participants and their needs in advance of the retreat, and skilful engagement of participants once on retreat. Established researchers are not necessarily confident writers and need as much consideration as novices and emerging researchers in this pedagogical model. The benefit of repeat participants, beyond that reported by Moore, Murphy and Murray (2010) and Grant (2006) is their contribution to establishing the $\mathrm{CoP}$ as the retreat begins.

Research publication output within the school improved over the two-year period, with retreat participants reporting substantial progress towards or completion of higher degrees, as well as many conference papers and/or journal articles. Although this cannot be directly linked to the retreats alone, a stronger research culture exists within the school now, publication output continues to grow steadily, and academics report valuing writing retreats as supportive strategies for research productivity. Reduced research funding has since restricted writing retreats to faculty-wide rather than school level. It is telling that the majority of places on these writing retreats are taken up by staff members from this particular school and that almost all of these participants have attended retreats before.

\section{REFERENCES}


Aitchison, C., B. Kamler and A. Lee. (Eds.). 2010. Publishing pedagogies for the Doctorate and beyond. London and New York: Routledge Taylor and Francis Group.

Aitchison, C. and A. Lee. 2006. Research writing: problems and pedagogies. Teaching in Higher Education 11(3): 265-278.

Badenhorst, C. 2007. Research writing: Breaking the boundaries. Pretoria: Van Schaik.

Bandura, A. 1977. Social learning theory. New Jersey: Prentice Hall.

Blaxter, L., C. Hughes and M. Tight. 1998. Writing on academic careers. Studies in Higher Education 23(3): 281-304.

Boud, D. and A. Lee. 2005. Peer learning as pedagogic discourse for research education. Studies in Higher Education 30(5): 501-515.

Brown, J. S. and P. Duguid. 1991. Organizational learning and communities of practice: Toward a unified view of working, learning and innovation. Organizational Science 2(1): 40-57.

Castle, J. 2017. Benefits of freewriting for academic staff engaged in a writing retreat. (Accepted for this Special Edition).

Castle, J. and M. Keane. (forthcoming). It was an oasis in a busy life, a busy city: The Centre for Learning, Teaching and Development writing retreat. Journal of Education.

Chandler, J., J. Barry and H. Clark. 2002. Stressing academe: The wear and tear of the new public management. Human Relations 55(9): 1051-1069.

Cox, A. 2005. What are Communities of Practice? A comparative review of four seminal works. Journal of Information Science 31(6): 537-540.

Dankoski, M., M. Palmer, J. Banks, R. Brutkiewicz, E. Walvoord, K. Hoffmann-Longtin, S. Bogdewic and G. Gopen. 2012. Academic writing: Supporting faculty in a critical competency for success. The Journal of Faculty Development 26(2): 47-54.

Deci, E. L. and R. M. Ryan. 1985. Intrinsic motivation and self-determination in human behavior. New York: Plenum.

Devlin, M. and A. Radloff. 2014. A structured writing programme for staff: Facilitating knowledge, skills, confidence and publishing outcomes. Journal of Further and Higher Education 38(2): 230248.

Elbow, P. and M. D. Sorcinelli. 2006. The faculty writing place: A room of our own. Change: The Magazine of Higher Learning 38(6): 17-22.

Galligan, L., P. Cretchley, L. George, K. Martin McDonald, J. McDonald and J. Rankin. 2003. Evolution and emerging trends of university writing groups. Queensland Journal of Educational Research 19(1): 28-41.

Grant, B. 2006. Writing in the company of other women: Exceeding the boundaries. Studies in Higher Education 31(4): 483-495.

Gouthro, P. 2014. Who gets to be a writer? Exploring identity and learning issues in becoming a fiction author. Studies in Continuing Education 36(2): 173-187.

Kapp, C. A., R. M. Albertyn and B. L. Frick. 2011. Writing for publication: An intervention to overcome barriers to scholarly writing. South African Journal of Higher Education 25(4): 741-759.

Keane, M. Quiet writing: Retreat as pedagogy. (Accepted for this Special Edition).

Lave, J. and E. Wenger. 1991. Situated learning: Legitimate peripheral participation. Learning in Doing. New York: Cambridge University Press.

Lee, A. and D. Boud. 2003. Writing groups, change and academic identity: Research development as local practice. Studies in Higher Education 28(2): 187-200.

Lee, A. and B. Kamler. 2008. Bringing pedagogy to doctoral publishing. Teaching in Higher Education 13(5): 511-523.

Li, L. C., J. M. Grimshaw, C. Nielsen, M. Judd, P. C. Coyte and I. D. Graham. 2009. Evolution of 
Wenger's concept of community of practice. Implementation Science 4(1): 11.

Lincoln, Y. S. and E. G. Guba. 1981. Effective evaluation: Improving the usefulness of evaluation results through responsive and naturalistic approaches. San Francisco, CA, US: Jossey-Bass.

Lundstrom, K. and W. Baker. 2009. To give is better than to receive: The benefits of peer review to the reviewer's own writing. Journal of Second Language Writing 18(1): 30-43.

Maxwell, J. A. 2005. Qualitative research design: An interactive approach. $2^{\text {nd }}$ ed. Thousand Oaks, CA: Sage Publications.

McGrail, M. R., C. M. Rickard and R. Jones. 2006. Publish or perish: A systematic review of interventions to increase academic publication rates. Higher Education Research and Development 25(1): 19-35.

Moore, S. 2003. Writing retreats for academics: Exploring and increasing the motivation to write. Journal of Further and Higher Education 27(3): 333-342.

Moore, S., M. Murphy and R. Murray. 2010. Increasing academic output and supporting equality of career opportunities: Can writers' retreats play a role? Journal of Faculty Development 24(3): 2130.

Morss, K. and R. Murray. 2001. Researching academic writing within a structured programme: Insights and outcomes. Studies in Higher Education 26(1): 35-59.

Murray, R. 2012. Developing a community of research practice. British Educational Research Journal 35(5): 783-800.

Murray, R. and S. Moore. 2006. The handbook of academic writing: A fresh approach. Maidenhead, England: Open University Press.

Murray, R. and M. Newton. 2009. Writing retreat as structured intervention: Margin or mainstream? Higher Education Research and Development 28: 541-553.

Olthouse, J. M. 2013. MFA Writers' relationships with writing. Journal of Advanced Academics 24(4): 259-274.

Petrova, P. and A. Coughlin. 2012. Using structured writing retreats to support novice researchers. International Journal for Researcher Development 3: 79-88.

Rule, P. and V. John. 2011. Your guide to case study research. Pretoria, SA: Van Schaik Publishers.

Ryan, R. M. and E. L. Deci. 2000. Intrinsic and extrinsic motivations. Contemporary Educational Psychology 25: 54-67.

Schneider, P. 2003. Writing alone: Writing with others. New York: Oxford University Press.

The Academy of Science of South Africa. 2009. The State of Science in South Africa. Pretoria: (ASSAf).

Wenger, E., R. McDermott and W. M. Snyder. 2002. Cultivating communities of practice: A guide to managing knowledge. Boston MA: Harvard Business School Press.

Wenger, E. 1998. Communities of practice: Learning, meaning and identity. Cambridge: Cambridge University Press.

Wolcott, H. F. 1990. Writing up qualitative research. Newbury Park: Sage Publications. 